\title{
Children with classic congenital adrenal hyperplasia experience salt loss and hypoglycemia: evaluation of adrenal crises during the first 6 years of life
}

\author{
Brigitte Odenwald, Uta Nennstiel-Ratzel, Helmuth-Günther Dörr'1, \\ Heinrich Schmidt ${ }^{2}$, Manfred Wildner and Walter Bonfig ${ }^{3,4}$
}

Bavarian Health and Food Safety Authority, Veterinärstr.2, D-85762 Oberschleißheim, Germany, ${ }^{1}$ Department of Pediatrics, University of Erlangen-Nürnberg, Erlangen, Germany, ${ }^{2}$ Department of Pediatrics, Ludwig-MaximiliansUniversity Munich (LMU), Munich, Germany, ${ }^{3}$ Department of Pediatrics, Technical University Munich (TUM), Munich, Germany and ${ }^{4}$ Department of Pediatrics, Klinikum Wels-Grieskirchen, Wels, Austria
Correspondence should be addressed to B Odenwald Email

birgit.odenwald@ Igl.bayern.de

\begin{abstract}
Objective: To evaluate adrenal crises after the start of treatment up to the age of 6 years in children with classic congenital adrenal hyperplasia (CAH).

Design: Analysis of data extracted from a population-based prospective long-term follow-up study of children detected in neonatal screening.

Methods: Data of 102 Bavarian children with classic CAH due to 21-hydroxylase deficiency were analyzed, using parental questionnaires and medical reports. Parent-reported hospital admissions of children diagnosed with acute health impairment were included in the analysis if salt loss (hyponatremia) or hypoglycemia was documented in the discharge summary.

Results: A total of 74 children (72.5\%) had no report of hospital admissions with salt loss or hypoglycemia during the observational period. However, in $27.5 \%$ of the children, 22 salt-wasting crises (seven of these also with low blood glucose) and 16 hypoglycemic episodes without salt loss were reported. Furthermore, the cumulative incidence for seizures was elevated; 13 children experienced seizures during hyponatremia or hypoglycemia. Most adrenal crises were triggered by infections, often with inappropriate emergency management, but in 11 cases hypoglycemia occurred unexpectedly, without evidence of severe illness and without any management errors. Frequency of adrenal crises was 6.5 per 100 patient years (95\% Cl: 4.6-8.8).

Conclusions: Crisis prevention remains a permanent challenge for families and physicians caring for children with classic $\mathrm{CAH}$. Expert care and compliance with emergency recommendations are crucial. Further research on the interactions among glucocorticoid deficiency, adrenomedullary dysfunction, and glucose metabolism is necessary for the prevention of hypoglycemia, especially in young CAH patients.
\end{abstract}

\section{Introduction}

21-Hydroxylase-deficient (21-OHD) classic congenital adrenal hyperplasia $(\mathrm{CAH})$ is a potentially lethal autosomal recessive endocrine disorder caused by mutations in the CYP21A2 gene. The disorder is characterized by (c) 2016 European Society of Endocrinology Printed in Great Britain cortisol deficiency and androgen excess, and in the most frequent and most severe salt-wasting form, there is also aldosterone deficiency (1). In addition, adrenomedullary dysfunction with impaired catecholamine secretion has

Published by Bioscientifica Ltd. 
been found (2). Continuous glucocorticoid therapy is required, combined with mineralocorticoid substitution in most cases, and published guidelines highly recommend regular examinations at a specialized endocrinology center (3).

Patients with classic $\mathrm{CAH}$ have a lifelong risk of adrenal crises, especially under conditions of major physical stress, because the physiological stress response is impaired. Typical clinical findings of adrenal crises are dehydration, hypotension, salt-wasting (hyponatremia and hyperkalemia), hypoglycemia, or altered mental status (4). Adrenal crises may present with weakness, vomiting, abdominal pain or confusion, and may cause shock, coma, and death, if untreated (5). For the prevention of adrenal crises in all conditions of major physical stress, such as trauma, infection, fever, or surgery, glucocorticoid doses must be augmented, and parenteral administration of glucocorticoids may be necessary (1). Medical identification should always be carried by the patient $(6,7,8)$. Information and education of $\mathrm{CAH}$ patients and their caregivers regarding clinical symptoms that indicate an imminent adrenal crisis and appropriate reactions are regarded as highly important $(9,10)$.

Early detection of $\mathrm{CAH}$ by neonatal screening has been widely acknowledged to prevent morbidity and mortality from severe adrenal crises before diagnosis $(6,11)$. However, thus far, little has been published about the success of crisis prevention in the years after detection by screening. Most reports on adrenal crises or clinical outcomes concern CAH patients who were born before the introduction of CAH neonatal screening $(12,13)$. Among the few studies on adrenal crises in patients with multiple causes of adrenal insufficiency $(14,15)$, there is only one study exclusively concerning CAH patients (16). In these studies, the frequency of adrenal crises ranged between 5 and 10 per 100 patient years, and crises were triggered mostly by infections and often by non-compliance with recommendations, or by treatment errors. In the literature, there are also several reports of deaths due to adrenal crises in $\mathrm{CAH}$ patients $(8,17,18,19)$. Reports on hypoglycemia in infants and young children with classic $\mathrm{CAH}$ are sparse, whereas clinical experience shows that hypoglycemia occurs in this young group of CAH patients.

The Bavarian prospective and population-based follow-up study of children detected after neonatal screening since 1999 has been initiated to evaluate longterm outcomes of neonatal screening. A first analysis has shown that screening could not prevent early stages of salt-wasting crises during the neonatal period in 27 of 114 infants, but severe or fatal adrenal crises before diagnosis and start of treatment could be avoided in all cases (20).

This study presents an evaluation of hospital admissions with salt loss or hypoglycemia in children with classic $\mathrm{CAH}$ during the first 6 years of life after the neonatal period.

\section{Subjects and methods}

The parents of all children diagnosed with 21-OHD classic CAH after neonatal screening in Bavaria from 1999 to 2011 were invited to participate in the Bavarian prospective long-term follow-up study. Written informed consent to complete regular questionnaires and to allow analysis of medical reports was required for participation. The study was approved by the ethics commission of the Bavarian State Chamber of Physicians. The observation period for this analysis covers the first 6 years of life, starting after the neonatal period, after diagnosis and start of treatment.

For identification and analyses of relevant episodes, data from parents' questionnaires at ages 1, 2, 4, and 6 years, and from hospital discharge summaries, were used. Parent-reported hospital admissions of children with acute health impairment were included in the analysis if salt loss (serum sodium $<132 \mathrm{mmol} / \mathrm{l}$ ) or hypoglycemia (blood glucose $<60 \mathrm{mg} / \mathrm{dl}$ or $<3.3 \mathrm{mmol} / \mathrm{l}$ ) were documented in the discharge summary. For the calculation of crisis frequency, a recently proposed definition (8) was used with slight modifications. Adrenal crisis was defined as a profound impairment of general health, with (A), at least two of the following clinical features: severe fatigue, nausea or vomiting, somnolence, hypotension, hyponatremia ( $<132 \mathrm{mmol} / \mathrm{l})$ or hyperkalemia, hypoglycemia; and (B), clinical deterioration precipitated by a glucocorticoid-deficient state, or clinical improvement after the administration of glucocorticoids.

The CYP21A2 genotype was classified in accordance with the nomenclature introduced by Wedell et al. (21) and used by Krone et al. (22), classifying compound heterozygotes by the less severely mutated allele. The Null group included deletions and most severe mutations (Q318X, R356W, d8bp, E6cluster), group A included severe mutations (intron 2 splice-site mutation homozygous or compound heterozygous with a group Null mutation), and group B included moderately milder mutations (I172N mutation homozygous or compound heterozygous with a group Null or A mutation).

Data for the calculation of prescribed regular daily doses of glucocorticoids were taken from parental questionnaires or from the discharge summaries. 
Parents' reactions to illness of their child were compared with recent 'sick day rules'. These recommendations include at least to triple the regular oral hydrocortisone dose, immediately, in cases of intercurrent illness with a temperature $\geq 38.5^{\circ} \mathrm{C}$ ( $\geq 101 \mathrm{~F}$ ), vomiting, or diarrhea. In cases of repeated vomiting, rectal or parenteral glucocorticoid should be administered promptly, and in such situations, parents are advised to immediately take their child to the nearest hospital $(10,23)$. Doubled glucocorticoid dosages, which had been recommended during the first years of the observation period, were classified as low stress dosages.

For the evaluation of developmental status, agerelated items covering important stages of psychomotor and speech development, called 'Grenzsteine der Entwicklung' (24), were part of the parents' regular questionnaires. These items are the validated screening tool for the development of children in the first 6 years of life, standardized with normative samples from the general population (25). Parental assessment of their child's development was validated using medical reports whenever possible.

All data were managed using Access databases, and analyzed with IBM SPSS Statistics for Windows, Version 22.0. (IBM Corp., Armonk, NY, USA) software, using $\chi^{2}$ or Mann-Whitney $U$ tests at a level of significance of $P<0.05$, where appropriate.

\section{Results}

\section{Cohort}

From 1999 to 2011, 114 children were diagnosed with 21-OHD classic CAH after neonatal screening in Bavaria. The parents of 102 children (89.5\%; 54 boys and 48 girls) gave written informed consent to participate in long-term follow-up; eight families did not consent to participation, and three families moved to unknown addresses. One child, diagnosed with both classic CAH and an additional severe metabolic disorder, which is life-threatening in all catabolic situations (medium-chain acyl-CoA dehydrogenase (MCAD) deficiency), died in the first year of life due to a severe infection (details unavailable), before the process of inclusion into the follow-up was finished. Mutation groups of the 102 children were: Null, $n=17$ (16.7\%); A, $n=58$ (56.9\%); B, $n=25$ (24.5\%); other or unknown, $n=2(2.0 \%)$. Around $23.5 \%$ of the children had a history of a salt-wasting crisis with electrolyte imbalance and typical clinical signs in the neonatal period before treatment was initiated (mutation groups: Null, $n=6$; A, $n=14 ; \mathrm{B}, n=4)$, and 87 children (85.3\%) were diagnosed with a salt-wasting $\mathrm{CAH}$ phenotype. Within the data collection period, 90 children reached 6 years of age, and 12 children reached 4 years of age. Thus, the number of patient years observed was 588 patient years.

\section{Quality of care and compliance}

Care and treatment of the $\mathrm{CAH}$ patients were highly concordant with guidelines and recommendations, with few exceptions.

All patients were treated with hydrocortisone, mostly within the recommended daily dosage range of $10-15 \mathrm{mg} / \mathrm{m}^{2}$ daily. Patients with group B mutations were treated with slightly but not significantly lower doses of hydrocortisone than patients with Null or A mutations (Table 1). Approximately $90 \%$ of patients also received fludrocortisone (group Null, 100\%; A, 95\%; B, 81\%). There were no significant differences in fludrocortisone dosage among the different mutation groups (Table 2).

All children had regular medical check-ups. However, four families started visiting a pediatric endocrinologist only after having experienced salt loss or hypoglycemia. At the child's age of 1 year, few parents, who had not been referred to an expert up to this time, admitted not knowing what to do in case of illness or surgery, whereas at the age of 2 years and older, all parents stated to be wellinformed of sick day management, and more than $70 \%$ reported having applied 'sick day rules' during the preceding year.

During the first years after the introduction of $\mathrm{CAH}$ newborn screening, only $63 \%$ of the parents reported

Table 1 Doses of hydrocortisone $\left(\mathrm{mg} / \mathrm{m}^{2}\right)$ by age and mutation group. Data are presented as median (IQR).

\begin{tabular}{|c|c|c|c|c|}
\hline \multirow[b]{2}{*}{ Mutation group } & \multicolumn{4}{|c|}{ Age } \\
\hline & 1 year & 2 years & 4 years & 6 years \\
\hline Null $(n=15)$ & 11.9 (10.7-14.3) & $12.4(9.1-13.8)$ & $13.4(11.3-16.1)$ & $12.9(12.0-14.9)$ \\
\hline $\mathrm{A}(n=48)$ & $11.1(9.9-13.2)$ & $12.3(11.5-13.3)$ & $12.4(11.3-14.2)$ & $13.9(11.6-15.2)$ \\
\hline $\mathrm{B}(n=21)$ & $10.3(9.2-13.4)$ & $11.2(9.9-12.9)$ & $12.3(11.7-13.9)$ & $12.9(11.8-13.9)$ \\
\hline Total & $11.2(9.8-13.6)$ & $12.3(10.6-13.2)$ & $12.4(11.5-14.5)$ & $13.2(11.8-15.1)$ \\
\hline
\end{tabular}


Table 2 Doses of fludrocortisone $\left(\mu \mathrm{g} / \mathrm{m}^{2}\right)$ by age and mutation group. Data are presented as median (IQR).

\begin{tabular}{|c|c|c|c|c|}
\hline \multirow[b]{2}{*}{ Mutation group } & \multicolumn{4}{|c|}{ Age } \\
\hline & 1 year & 2 years & 4 years & 6 years \\
\hline Null $(n=15)$ & 166 (122-239) & $96(84-136)$ & 66 (37-103) & $50(36-60)$ \\
\hline $\mathrm{A}(n=45)$ & $209(126-245)$ & 103 (90-159) & $77(71-88)$ & $61(51-66)$ \\
\hline $\mathrm{B}(n=17)$ & $175(119-235)$ & $98(83-135)$ & 79 (69-113) & $64(55-65)$ \\
\hline Total & 189 (124-241) & $98(88-154)$ & 77 (67-101) & $61(51-65)$ \\
\hline
\end{tabular}

having a steroid treatment alert card for their child, but this percentage increased to $95 \%$ after the German $\mathrm{CAH}$ support group started distributing special CAH Emergency Health Cards.

Eleven different specialized centers (seven in Bavaria, four in other regions) were involved in the pediatric endocrine care of the $\mathrm{CAH}$ patients. Because these centers usually only exist in big cities, numerous families travel long distances for their regular expert visits, and in case of emergencies, $47 \%$ of the families contacted local emergency services. Parents repeatedly reported difficulties in attaining the necessary parenteral glucocorticoid application for their child in case of injury or illness, because the local medical staff or emergency services were not familiar with this disorder, and were unwilling to pay attention to their $\mathrm{CAH}$ emergency documents.

\section{Frequency and distribution of salt loss and hypoglycemia}

A total of $74 \mathrm{CAH}$ children (72.5\%) had no report of any salt-wasting or hypoglycemic episodes in the first 6 years of life after the neonatal period. For the other $28 \mathrm{CAH}$ children, 22 salt-losing events (seven of these were associated with hypoglycemia) and 16 hypoglycemic events without salt loss were reported. Details are given in Table 3.

According to the discharge summaries, which were available and analyzed for $90 \%$ of the 83 reported hospital admissions with acute health impairment, only the 38 hospital admissions with salt loss or hypoglycemia met the definition of an adrenal crisis. Thus, the frequency of adrenal crises was 6.5 per 100 patient years (95\% CI: 4.4-8.8).

In all cases, serum electrolytes were documented, whereas in seven cases of salt loss, blood glucose was not mentioned in the discharge letter. Salt loss was mostly characterized by serum hyponatremia; in only two cases, serum hyperkalemia was documented (episode numbers 19 and 23). There were no reports of arterial hypotension.
All children with reports of an adrenal crisis were diagnosed with a salt-wasting $\mathrm{CAH}$ phenotype. Of these, 19 children had only one adrenal crisis, eight children had two incidents, and one child had three incidents. The CYP21A2 mutation groups of children experiencing salt loss were A $(n=16), \mathrm{B}(n=3)$, and unknown $(n=1)$. All children with combined salt loss and low blood glucose belonged to the mutation group A. In mutation group Null, which is characterized by the most severe enzyme deficiency, there was no report of salt loss after the neonatal period. Hypoglycemia was reported for the mutation groups Null $(n=4), \mathrm{A}(n=7)$, and B $(n=1)$. Figure 1 shows the percentage of the different incident types within each mutation group and for the whole cohort. Group B shows the lowest percentage of children with incidents of all kinds, but this difference is not statistically significant.

Figure 2 shows the age of children at the time of adrenal crises. Hypoglycemia was only reported after the first year of life, and incident risk appears to have decreased after the age of 4 years, but there was no statistical significance for age differences.

\section{Conditions of salt loss}

All salt-wasting events occurred during infections. Patients $5,9,13$, and 28 (episodes 8, 14, 19, and 38) had salt loss during severe or sudden infections under adequate glucocorticoid treatment. The other 18 salt-wasting events were preceded by intercurrent infections (nine gastrointestinal, five respiratory, and four other) of a 1-4 day duration, all with a temperature $\geq 38.5{ }^{\circ} \mathrm{C}(101.3 \mathrm{~F})$, and/or vomiting. In each of these 18 cases, the children had either not received tripled or higher hydrocortisone stress dosages, or had been on oral glucocorticoid administration only (despite recurrent vomiting), or both. The prescribed regular daily doses of hydrocortisone and fludrocortisone before salt-wasting events did not differ from the doses reported for the whole cohort. Comparison of 'history of neonatal adrenal crisis', 


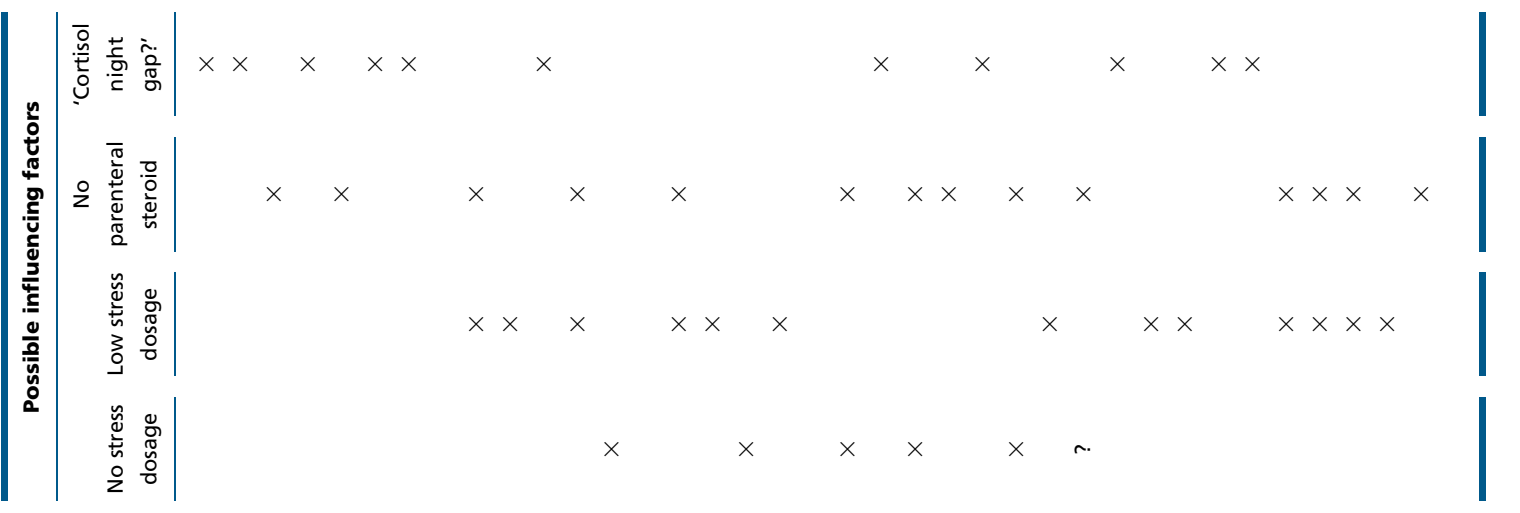

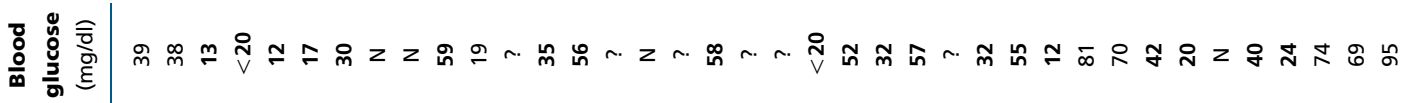

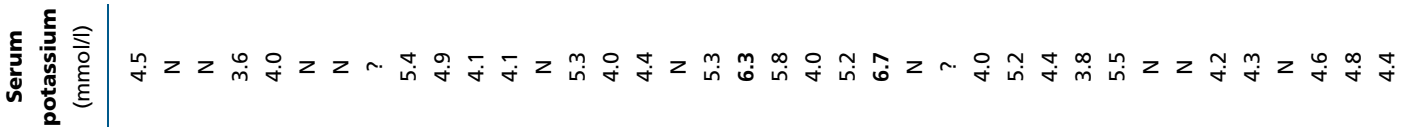

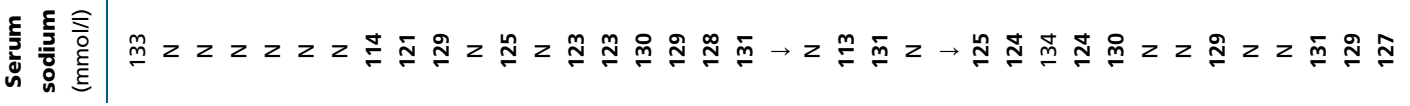

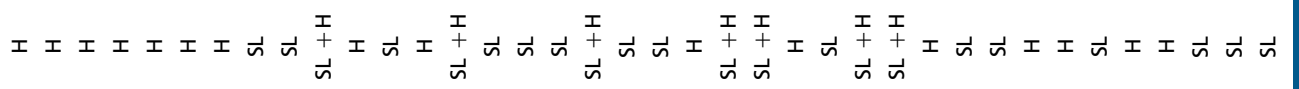

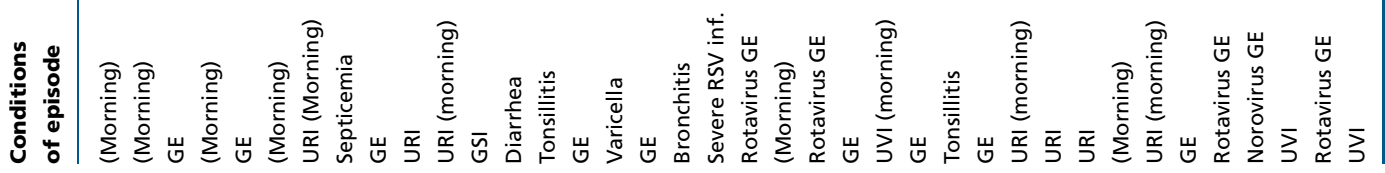

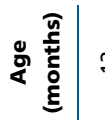

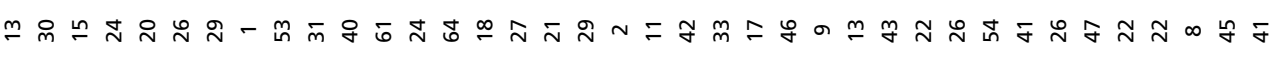

吾| $\overline{\bar{z}} \overline{\bar{z}} \overline{\bar{z}} \overline{\bar{z}} \overline{\bar{z}} \overline{\bar{z}} \overline{\bar{z}} \overline{\bar{z}}$

$\dot{0}$ $-\sim$ 


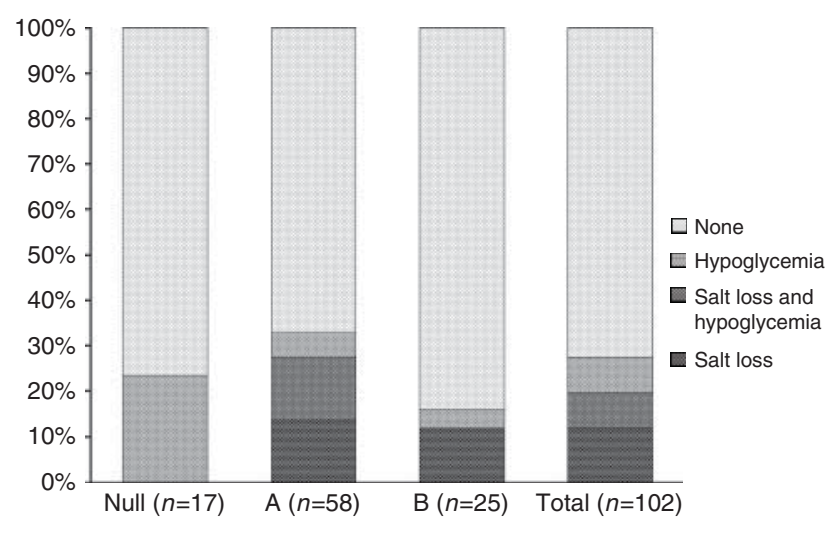

\section{Figure 1}

Percentage of children with salt loss and hypoglycemia in the different mutation groups.

migration background or parents' educational status between the groups of children with and without compliance errors did not show any significant differences.

The children's general appearance at hospital admission was described as 'ill', 'weak', 'poor', or 'distressed'. Eight feverish children had seizures during hyponatremia with or without hypoglycemia. Once admitted to the hospital, all children recovered soon under an oral $(n=9)$ or parenteral $(n=13)$ glucocorticoid stress dosage and i.v. application of fluids/sodium.

\section{Conditions of hypoglycemia}

In contrast to infection-related salt-wasting episodes, hypoglycemia often appeared unexpectedly, mostly in the early morning, in previously unimpaired children. In five out of 16 hypoglycemic events, gastrointestinal infections with inadequate glucocorticoid stress dosage could be identified as possible predisposing factor. In the other 11 cases, according to the physician's and parent's judgments, regular medication had been given as prescribed, and no condition requiring stress dosage had been observed. Six children had appeared completely healthy the day before, and five children had had minor infections such as a common cold, or cough, without fever or vomiting. The prescribed regular daily doses of hydrocortisone were slightly lower before hypoglycemic episodes (median, 11.2; IQR, 10.2-12.7 $\mathrm{mg} / \mathrm{m}^{2}$ ), than in the whole cohort (median, 12.3; IQR, 10.8-14.0 mg/m²), but this difference was not statistically significant $(P=0.07)$.

In all but one of the cases, hypoglycemia was severe, with blood glucose concentrations between 12 and
$42 \mathrm{mg} / \mathrm{dl}(0.66-2.31 \mathrm{mmol} / \mathrm{l})$, and with neurologic symptoms: six children had generalized seizures, and for 13 hypoglycemic episodes, loss of consciousness was reported. Parents immediately called emergency services or took their child to the nearest hospital. All children were treated with an i.v. application of glucose and fluids, as well as glucocorticoid stress dosages (eight parenteral and eight oral).

The attending pediatric endocrinologists suggested a 'cortisol night gap' to be the causative factor for the 11 hypoglycemic morning incidents. To protect these children from severe hypoglycemia, hydrocortisone timetables were changed from three to four times daily, introducing a late night or early morning dose and thus reducing the time span between the evening/night and morning hydrocortisone dose from a maximum of 9-10 h to 6-7 h. In addition, families were educated and equipped with point-of-care glucose monitoring systems.

\section{Frequency of seizures}

In this cohort of 102 children with classic CAH, 18 children had at least one seizure within the first 6 years of life (including common febrile seizures). Eight feverish children had seizures during hyponatremia, and five children had seizures during hypoglycemia; additionally, one child had neonatal seizures due to cerebral edema, one child was diagnosed with epilepsy, and three children had febrile seizures without hyponatremia or hypoglycemia (probably common febrile seizures). Fifteen of these children had only one seizure; three children (patients 18 and 25, and the child diagnosed with epilepsy) had

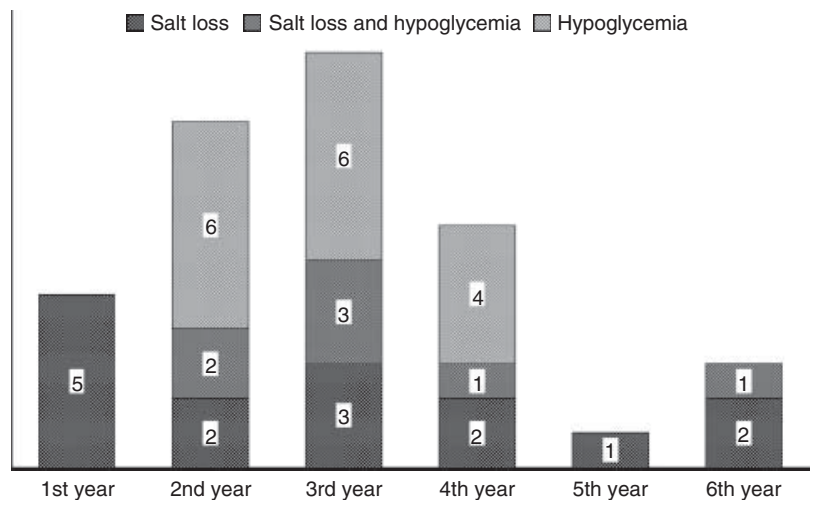

Figure 2

Number of events with salt loss and hypoglycemia by age of children. 
repeated seizures during the observational period. The overall rate for having experienced at least one seizure in the first 6 years of life was $17.6 \%$ (95\% CI: $10.8-26.4 \%$ ).

\section{Development}

Analysis of the children's developmental status at ages 4 and 6 years did not show any differences among children with and without documented salt-wasting, hypoglycemia, or seizures during the first 6 years of life. Neither of the group results differed from the general population standard values for the respective ages.

\section{Discussion}

This study evaluated the frequency and etiology of adrenal crises in CAH children after the neonatal period, to assess the efficacy of current crisis prevention strategies.

The prevention, or identification and appropriate handling, of an adrenal crisis are a complex challenge for both the parents and the medical staff $(26,27)$. Conditions of acute illness or accidental trauma, which require the consideration of applying a stress regimen, are common in childhood. Parents have to cope with the task of constant alertness and responsibility (28), without being overprotective. In case of emergency, well-informed parents may be confronted with health professionals who are inexperienced in managing the rare condition of an imminent adrenal crisis $(7,8,9,27)$.

For the majority of children, crisis prevention during the first 6 years after the diagnosis proved successful. Parents' statements concerning compliance with medication, emergency cards, or applying sick day rules show a generally high level of education and consciousness, with a tendency towards more uncertainty during the first year of life before the first critical episodes have been managed. Lack of expert care, provided by a specialized pediatric endocrinologist, appeared to be a disadvantage.

In spite of preventive efforts, adrenal crises could not always be avoided. In some cases, symptoms appeared very rapidly, leaving no time frame for special preventive therapy. In other cases, delays or errors in glucocorticoid management, caused by the caregivers or by general medical staff, may have contributed to the progression of clinical symptoms and metabolic deterioration. Noncompliance with sick day rules was observed among all educational levels of parents, possibly caused by underestimation of the situation or by the wish to avoid an i.m. injection, hospitalization, or confrontation with medical staff. There were complaints about difficulties in convincing healthcare workers to observe the presented emergency documents. These findings support the need for optimal crisis prevention strategies $(14,16)$, including education, training, empowerment and support of all parents and patients $(9,26,29)$, clear emergency documents $(7,30)$, easily accessible information for professionals (31), and the sensitization of healthcare workers $(9,16,27,32)$. The high number of cases without parenteral application of a glucocorticoid in spite of repeated vomiting might be reduced if - instead of i.m. injection - s.c. glucocorticoid injection or a 'hydrocortisone pen' could be established for emergency use in the future $(8,32,33)$. As problems related to a lack of experience among health professionals are characteristic of rare diseases and not unique to $\mathrm{CAH}$, they might be overcome by a generally raised awareness about these so-called 'orphan diseases' in the healthcare system (31).

With the exception of the one tragic death in the first year of life, which was probably caused by the extremely rare coincidence of $\mathrm{CAH}$ and MCAD deficiency and a severe acute infection, there were no fatal outcomes and all other children could be stabilized. Moreover, thus far, there are no indications for assuming that the adrenal crises might have affected the children's further neurological development, with the limitation being that the children's development was not assessed by detailed expert testing.

Only few children had more than one crisis. As expected, most crises occurred in children with severe mutations (groups Null or A), but also children with milder mutations (group B) were affected. However, saltwasting phenotypes caused by these mutations (group B) have already been described in the literature $(21,34)$. Infants with group Null mutations had salt-wasting crises in the neonatal period before diagnosis, but after the neonatal period there were only reports of hypoglycemia, none of salt loss, for this group. Although this appears to be a remarkable observation, in consideration of the small number of cases a random effect cannot be excluded, particularly as possible explanations like different medication dosages or better compliance in group Null are not confirmed by our data.

Thus far, no definition for adrenal crises has been available; therefore, the recently proposed definition (8) proved very helpful. Part A of this definition, comprising clinical features, was applied completely. The original mandatory condition B was modified as follows: 'Parenteral glucocorticoid administration followed by clinical improvement' was changed to 'clinical deterioration precipitated by a glucocorticoid-deficient state or clinical 
improvement after the administration of glucocorticoids'. As a result of this modification, the method for adrenal crisis management at the hospital (e.g., oral glucocorticoid stress dosing) cannot lead to the exclusion of obvious adrenal crises. However, in spite of differing definitions, the number of adrenal crises per patient years found in our cohort was similar to that of a German group of patients, aged 18-69 years, reported in 2012 (16). Due to a small number of events, the crisis frequency has a wide confidence interval. Variations in the adrenal crisis definition may lead to marginal changes in the calculated crisis frequency, but finally do not influence the conclusions.

All salt-wasting crises had an obvious precipitating factor, mostly infectious, and in many of these cases, the reported circumstances suggested that with an immediate application of current sick day recommendations, electrolyte disturbance might have been avoidable. However, an explanation is more difficult for several cases of symptomatic hypoglycemia, which occurred despite plausible documentation of compliance with treatment and sick day rules. The prevention of severe hypoglycemia seems not to be completely covered by the current treatment recommendations, although there are reports of hypoglycemia $(35,36,37,38,39,40)$ and adrenomedullary dysfunction $(2,41,42)$ in limited CAH study populations. For example, in a French cohort of 45 children diagnosed with classic CAH between 1981 and 1997, at ages 1-5 years and already under treatment, eight patients had severe hypoglycemic events, two of them lethal, while only three patients had a salt-wasting crisis (18). A causal relationship between adrenomedullary dysfunction and hypoglycemia is regarded as very likely (6). Some reports contain recommendations for glucose monitoring or providing ill $\mathrm{CAH}$ children with carbohydrates in addition to the glucocorticoid stress dosage $(6,43)$. In our cohort, daily hydrocortisone doses in the lower range of the recommended $10-15 \mathrm{mg} / \mathrm{m}^{2}$ daily, and medication timetables resulting in a longer cortisol night gap, may have contributed to a predisposition to hypoglycemia. Thus, altered dosage recommendations for young CAH children or new drugs with a delayed hydrocortisone release providing higher cortisol levels in the early morning hours $(44,45)$ could be promising approaches in the future. Probably not all classic CAH patients are equally at risk for hypoglycemia. Mutation group Null appeared to be associated with the highest risk, but, due to the small number of cases, reliable identification of risk factors is difficult. Investigation of the interactions among glucocorticoid deficiency, adrenomedullary function, and glucose metabolism, as well as identifying $\mathrm{CAH}$ patients at a high risk for hypoglycemia and developing specific prevention strategies are important issues for further research (6).

Sudden seizures are known to be the extremely frightening events for parents (46), and the incidence of seizures in this pediatric CAH cohort was surprisingly high. According to past reports, a seizure rate of about 3-5\% can be expected during the first years of life for European children $(47,48)$. In the German representative Children's Health Study KiGGS (49), this rate was 3.5\% (95\% CI: 3.3-3.8\%). Thus, the overall seizure rate of $17.6 \%$ in the CAH cohort was significantly elevated. An even higher rate (25.4\%) has been reported for an English cohort of 59 children with saltwasting CAH, born between 1968 and 1988 (12), but to our knowledge, seizure rates in $\mathrm{CAH}$ children have not been the focus of research thus far. CAH-associated brain abnormalities, possibly caused by hormonal or metabolic factors, have occasionally been reported in the literature $(50,51,52)$; whether such abnormalities might have contributed to an elevated seizure vulnerability in our cohort, cannot be assessed without further neurologic studies. However, as both hyponatremia and hypoglycemia are known to cause symptomatic seizures (48), the elevation of the seizure rate can very likely be explained by these two factors, and it may be assumed that the prevention of salt-wasting crises and hypoglycemia could also prevent seizures in CAH children.

This analysis was limited by the relatively small number of cases, which makes significant comparison of subgroups or identification of risk factors difficult. For the $10.5 \%$ of patients who were lost to follow-up, no information about adrenal crises and development were available. For the patients included in follow-up, although most parents appreciate and support the follow-up study and fill out their questionnaires carefully, under reporting of crises could have been possible. Some hospital admissions may have been omitted, and, in some cases, an adrenal crisis may have been managed at home, without medical documentation and without laboratory tests. Thus, the true crisis incidence may have been underestimated. However, a higher crisis rate would only strengthen the need for concerted preventive efforts and further research.

Despite these limitations, the population-based and prospective approach, which included patients from numerous medical centers, and the high follow-up rate, allowed the extensive collection of detailed and valuable information about the adrenal crises in $\mathrm{CAH}$ children. Taken together, the results confirmed the success and importance of crisis prevention, and in particular, emphasized the necessity of further investigation of the 
clinical relevance of adrenomedullary dysfunction in $\mathrm{CAH}$. Caregivers of CAH children need continuous active support for their demanding responsibility, and they need expert care and skilled physicians who are able to deal with the management of a rare disorder, even in case of emergency. Although long-term outcomes for this cohort of $\mathrm{CAH}$ children do not seem to be altered by the reported episodes of salt loss or hypoglycemia, each adrenal crisis is potentially harmful and should be avoided.

\section{Declaration of interest}

The authors declare that there is no conflict of interest that could be perceived as prejudicing the impartiality of the research reported.

\section{Funding}

This research did not receive any specific grant from any funding agency in the public, commercial or not-for-profit sector.

\section{Author contribution statement}

Study concept and design: U Nennstiel-Ratzel, B Odenwald, W Bonfig; acquisition of data: B Odenwald, $U$ Nennstiel-Ratzel; Analysis of data: B Odenwald; interpretation of data: B Odenwald, W Bonfig, U NennstielRatzel, H-G Dörr, H Schmidt; drafting the manuscript: B Odenwald; revision of the manuscript: W Bonfig, U Nennstiel-Ratzel, M Wildner, H-G Dörr, $\mathrm{H}$ Schmidt.

\section{Acknowledgements}

The authors would like to thank the Bavarian screening and follow-up teams for their support, the physicians and hospitals for providing clinical data, and the families for answering so many questions.

\section{References}

1 White PC \& Speiser PW. Congenital adrenal hyperplasia due to 21-hydroxylase deficiency. Endocrine Reviews 200021 245-291. (doi:10.1210/edrv.21.3.0398)

2 Merke DP, Chrousos GP, Eisenhofer G, Weise M, Keil MF, Rogol AD, Van Wyk JJ \& Bornstein SR. Adrenomedullary dysplasia and hypofunction in patients with classic 21-hydroxylase deficiency. New England Journal of Medicine 2000343 1362-1368. (doi:10.1056/NEJM200011093431903)

3 Clayton PE, Miller WL, Oberfield SE, Ritzen EM, Sippell WG \& Speiser PW. Consensus statement on 21-hydroxylase deficiency from the European Society for Paediatric Endocrinology and the Lawson Wilkins Pediatric Endocrine Society. Hormone Research 200258 188-195. (doi:10.1159/000065490)

4 Shulman DI, Palmert MR \& Kemp SF. Adrenal insufficiency: still a cause of morbidity and death in childhood. Pediatrics 2007119 e484-e494. (doi:10.1542/peds.2006-1612)

5 de Herder WW \& van der Lely AJ. Addisonian crisis and relative adrenal failure. Reviews in Endocrine \& Metabolic Disorders 20034 143-147. (doi:10.1023/A:1022938019091)
6 Speiser PW, Azziz R, Baskin LS, Ghizzoni L, Hensle TW, Merke DP, Meyer-Bahlburg HF, Miller WL, Montori VM, Oberfield SE et al. Congenital adrenal hyperplasia due to steroid 21-hydroxylase deficiency: an Endocrine Society clinical practice guideline. Journal of Clinical Endocrinology and Metabolism 201095 4133-4160. (doi:10.1210/jc.2009-2631)

7 Grossman A, Johannsson G, Quinkler M \& Zelissen P. Therapy of endocrine disease: perspectives on the management of adrenal insufficiency: clinical insights from across Europe. European Journal of Endocrinology/European Federation of Endocrine Societies 2013169 R165-R175. (doi:10.1530/EJE-13-0450)

8 Allolio B. Extensive expertise in endocrinology. Adrenal crisis. European Journal of Endocrinology/European Federation of Endocrine Societies 2015 172 R115-R124. (doi:10.1530/EJE-14-0824)

9 Auchus RJ, Witchel SF, Leight KR, Aisenberg J, Azziz R, Bachega TA, Baker LA, Baratz AB, Baskin LS, Berenbaum SA et al. Guidelines for the development of comprehensive care centers for congenital adrenal hyperplasia: guidance from the CARES foundation initiative. International Journal of Pediatric Endocrinology 20102010275213. (doi:10.1186/1687-9856-2010-275213)

10 Dörr H-G. Adrenogenitales Syndrom (AGS). In Therapie-Handbuch Innere Medizin, edn 1, ch. 8, pp 821-825. Eds BM Domschke W, Hohenberger W, Meinertz T, Possinger K \& Reinhardt D. Munich: Urban \& Fischer, 2011.

11 Riepe FG \& Sippell WG. Recent advances in diagnosis, treatment, and outcome of congenital adrenal hyperplasia due to 21-hydroxylase deficiency. Reviews in Endocrine \& Metabolic Disorders 20078 349-363. (doi:10.1007/s11154-007-9053-1)

12 Donaldson MD, Thomas PH, Love JG, Murray GD, McNinch AW \& Savage DC. Presentation, acute illness, and learning difficulties in salt wasting 21-hydroxylase deficiency. Archives of Disease in Childhood 1994 70 214-218. (doi:10.1007/s11154-007-9053-1)

13 Swerdlow AJ, Higgins CD, Brook CG, Dunger DB, Hindmarsh PC, Price DA \& Savage MO. Mortality in patients with congenital adrenal hyperplasia: a cohort study. Journal of Pediatrics 1998133 516-520. (doi:10.1016/S0022-3476(98)70060-5)

14 Hahner S, Loeffler M, Bleicken B, Drechsler C, Milovanovic D, Fassnacht M, Ventz M, Quinkler M \& Allolio B. Epidemiology of adrenal crisis in chronic adrenal insufficiency: the need for new prevention strategies. European Journal of Endocrinology/European Federation of Endocrine Societies 2010162 597-602. (doi:10.1530/EJE-09-0884)

15 Hahner S, Spinnler C, Fassnacht M, Burger-Stritt S, Lang K, Milovanovic D, Beuschlein F, Willenberg HS, Quinkler M \& Allolio B. High incidence of adrenal crisis in educated patients with chronic adrenal insufficiency: a prospective study. Journal of Clinical Endocrinology and Metabolism 2015100 407-416. (doi:10.1210/ jc.2014-3191)

16 Reisch N, Willige M, Kohn D, Schwarz HP, Allolio B, Reincke M, Quinkler M, Hahner S \& Beuschlein F. Frequency and causes of adrenal crises over lifetime in patients with 21-hydroxylase deficiency. European Journal of Endocrinology/European Federation of Endocrine Societies 2012 167 35-42. (doi:10.1530/EJE-12-0161)

17 Cleveland WW, Green OC \& Wilkins L. Deaths in congenital adrenal hyperplasia. Pediatrics 196229 3-17.

18 Pinto G, Tardy V, Trivin C, Thalassinos C, Lortat-Jacob S, NihoulFekete C, Morel Y \& Brauner R. Follow-up of 68 children with congenital adrenal hyperplasia due to 21-hydroxylase deficiency: relevance of genotype for management. Journal of Clinical Endocrinology and Metabolism 200388 2624-2633. (doi:10.1210/jc.2002-021433)

19 Falhammar H, Frisen L, Norrby C, Hirschberg AL, Almqvist C, Nordenskjold A \& Nordenstrom A. Increased mortality in patients with congenital adrenal hyperplasia due to 21-hydroxylase deficiency. Journal of Clinical Endocrinology and Metabolism 201499 E2715-E2721. (doi:10.1210/jc.2014-2957)

20 Odenwald B, Dorr HG, Bonfig W, Schmidt H, Fingerhut R, Wildner M \& Nennstiel-Ratzel U. Classic congenital adrenal hyperplasia due to 
21-hydroxylase-deficiency: 13 years of neonatal screening and follow-up in Bavaria. Klinische Pädiatrie 2015227 278-283.

21 Wedell A, Thilen A, Ritzen EM, Stengler B \& Luthman H. Mutational spectrum of the steroid 21-hydroxylase gene in Sweden: implications for genetic diagnosis and association with disease manifestation. Journal of Clinical Endocrinology and Metabolism 199478 1145-1152.

22 Krone N \& Arlt W. Genetics of congenital adrenal hyperplasia. Best Practice \& Research. Clinical Endocrinology \& Metabolism 200923 181-192. (doi:10.1016/j.beem.2008.10.014)

23 White PC \& Speiser PW. Long-term consequences of childhood-onset congenital adrenal hyperplasia. Best Practice \& Research. Clinical Endocrinology \& Metabolism 200216 273-288. (doi:10.1053/beem. 2002.0198)

24 Michaelis R, Berger R, Nennstiel-Ratzel U \& Krägeloh-Mann I. Validated and partially validated boundary stones of development. Developmental screening during the first 6 years of life. Monatsschrift für Kinderheilkunde 2013161 898-910.

25 Nennstiel-Ratzel U, Lüders A, Arenz S, Wildner M \& Michaelis R. Elternfrageboegen zu Grenzsteinen der kindlichen Entwicklung im Alter von 1 bis 6 Jahren. Kinderaerztliche Praxis 201384 106-114.

26 Fleming LK, Rapp CG \& Sloane R. Caregiver knowledge and selfconfidence of stress dosing of hydrocortisone in children with congenital adrenal hyperplasia. Journal of Pediatric Nursing 201126 e55-e60. (doi:10.1016/j.pedn.2011.03.009)

27 Wass JA \& Arlt W. How to avoid precipitating an acute adrenal crisis. BMJ 2012345 e6333. (doi:10.1136/bmj.e6333)

28 Hindmarsh PC. Management of the child with congenital adrenal hyperplasia. Best Practice \& Research. Clinical Endocrinology \& Metabolism 200923 193-208. (doi:10.1016/j.beem.2008.10.010)

29 Moloney S \& Dowling M. Early intervention and management of adrenal insufficiency in children. Nursing Children and Young People 201224 25-28. (doi:10.7748/ncyp2012.09.24.7.25.c9275)

30 Quinkler M, Beuschlein F, Hahner S, Meyer G, Schofl C \& Stalla GK. Adrenal cortical insufficiency - a life threatening illness with multiple etiologies. Deutsches Ärzteblatt International 2013110 882-888.

31 NAMSE, Ed. (National Action League for People with Rare Diseases). German National Plan of Action for People with Rare Diseases. Available at http://www.europlanproject.eu/DocumentationAttachment/NATIONALPLANS_GERMAN_2013_en.pdf Bonn, 2013.

32 Hahner S, Hemmelmann N, Quinkler M, Beuschlein F, Spinnler C \& Allolio B. Timelines in the management of adrenal crisis - targets, limits and reality. Clinical Endocrinology 201582 497-502. (doi:10.1111/cen. 12609)

33 Hahner S, Burger-Stritt S \& Allolio B. Subcutaneous hydrocortisone administration for emergency use in adrenal insufficiency. European Journal of Endocrinology/European Federation of Endocrine Societies 2013 169 147-154. (doi:10.1530/EJE-12-1057)

34 New MI, Abraham M, Gonzalez B, Dumic M, Razzaghy-Azar M, Chitayat D, Sun L, Zaidi M, Wilson RC \& Yuen T. Genotype-phenotype correlation in 1,507 families with congenital adrenal hyperplasia owing to 21-hydroxylase deficiency. PNAS 2013110 2611-2616. (doi:10.1073/pnas.1300057110)

35 White FP \& Sutton LE. Adrenogenital syndrome with associated episodes of hypoglycemia. Journal of Clinical Endocrinology and Metabolism 195111 1395-1402. (doi:10.1210/jcem-11-11-1395)

36 Mackinnon J \& Grant DB. Hypoglycaemia in congenital adrenal hyperplasia. Archives of Disease in Childhood 1977 52 591-593. (doi:10.1136/adc.52.7.591)
37 Gemelli M, De Luca F \& Barberio G. Hypoglycaemia and congenital adrenal hyperplasia. Acta Paediatrica Scandinavica 197968 285-286. (doi:10.1111/j.1651-2227.1979.tb05005.x)

38 Hinde FR \& Johnston DI. Hypoglycaemia during illness in children with congenital adrenal hyperplasia. Br Med J (Clin Res Ed) 1984289 1603-1604. (doi:10.1136/bmj.289.6458.1603)

39 Artavia-Loria E, Chaussain JL, Bougneres PF \& Job JC. Frequency of hypoglycemia in children with adrenal insufficiency. Acta Endocrinologica. Supplementum 1986113 275-278. (doi:10.1530/acta.0. 112S275)

40 Keil MF, Bosmans C, Van Ryzin C \& Merke DP. Hypoglycemia during acute illness in children with classic congenital adrenal hyperplasia. Journal of Pediatric Nursing 201025 18-24. (doi:10.1016/j.pedn.2008. 06.003)

41 Tutunculer F, Saka N, Arkaya SC, Abbasoglu S \& Bas F. Evaluation of adrenomedullary function in patients with congenital adrenal hyperplasia. Hormone Research 200972 331-336. (doi:10.1159/000249160)

42 Kim MS, Ryabets-Lienhard A, Bali B, Lane CJ, Park AH, Hall S \& Geffner ME. Decreased adrenomedullary function in infants with classical congenital adrenal hyperplasia. Journal of Clinical Endocrinology and Metabolism 201499 E1597-E1601. (doi:10.1210/jc.2014-1274)

43 Merke DP \& Bornstein SR. Congenital adrenal hyperplasia. Lancet 2005 365 2125-2136. (doi:10.1016/S0140-6736(05)66736-0)

44 Moeller H. Chronopharmacology of hydrocortisone and 9 alphafluorhydrocortisone in the treatment for congenital adrenal hyperplasia. European Journal of Pediatrics 1985144 370-373. (doi:10.1007/BF00441780)

45 Mallappa A, Sinaii N, Kumar P, Whitaker MJ, Daley LA, Digweed D, Eckland DJ, Van Ryzin C, Nieman LK, Arlt W et al. A phase 2 study of Chronocort, a modified-release formulation of hydrocortisone, in the treatment of adults with classic congenital adrenal hyperplasia. Journal of Clinical Endocrinology and Metabolism 2015100 1137-1145. (doi:10.1210/jc.2014-3809)

46 Baumer JH, David TJ, Valentine SJ, Roberts JE \& Hughes BR. Many parents think their child is dying when having a first febrile convulsion. Developmental Medicine and Child Neurology 198123 462-464. (doi:10.1111/j.1469-8749.1981.tb02019.x)

47 Hauser AW. The prevalence and incidence of convulsive disorders in children. Epilepsia 199435 (Suppl. 2) S1-S6. (doi:10.1111/j.1528-1157. 1994.tb05932.x)

48 Siemes H. Anfälle, die nicht die Diagnose Epilepsie erfordern (Gelegenheitsanfälle). In Epilepsien bei Kindern und Jugendlichen, pp 136-141. Bern: Verlag Hans Huber, 2009.

49 Robert Koch Institute RKI. The German Health Survey for Children and Adolescents 2003-2006, Public Use File 4. Version. doi:10.7797/ 9-200306-1-1-4.

50 Saito Y, Ogawa T, Nagaishi J, Inoue T, Maegaki Y \& Ohno K. Laminar cortical necrosis in adrenal crisis: sequential changes on MRI. Brain \& Development 200830 77-81. (doi:10.1016/j.braindev.2007.05.007)

51 Lee S, Sanefuji M, Watanabe K, Uematsu A, Torisu H, Baba H, Kira R, Takada Y, Ishizaki Y, Toyoshima $\mathrm{M}$ et al. Clinical and MRI characteristics of acute encephalopathy in congenital adrenal hyperplasia. Journal of the Neurological Sciences 2011306 91-93. (doi:10.1016/j.jns. 2011.03.037)

52 Salpietro V, Polizzi A, Di Rosa G, Romeo AC, Dipasquale V, Morabito P, Chirico V, Arrigo T \& Ruggieri M. Adrenal disorders and the paediatric brain: pathophysiological considerations and clinical implications. International Journal of Endocrinology 20142014 282489. (doi:10.1155/ 2014/282489)

Received 31 July 2015

Revised version received 8 November 2015

Accepted 12 November 2015 